\title{
Review
}

\section{Update on the Roles of Rice MAPK Cascades}

\author{
Jie Chen $(\mathbb{1}$, Lihan Wang $(\mathbb{1})$ and Meng Yuan *(D) \\ National Key Laboratory of Crop Genetic Improvement, National Center of Plant Gene Research (Wuhan), \\ Huazhong Agricultural University, Wuhan 430070, China; shijiechen@webmail.hzau.edu.cn (J.C.); \\ lhwang@webmail.hzau.edu.cn (L.W.) \\ * Correspondence: myuan@mail.hzau.edu.cn
}

check for updates

Citation: Chen, J.; Wang, L.; Yuan, M. Update on the Roles of Rice MAPK Cascades. Int. J. Mol. Sci. 2021, 22, 1679. https://doi.org/10.3390/ ijms22041679

Academic Editor: Atsushi Matsuzawa Received: 22 December 2020

Accepted: 4 February 2021

Published: 7 February 2021

Publisher's Note: MDPI stays neutral with regard to jurisdictional claims in published maps and institutional affiliations.

Copyright: (C) 2021 by the authors Licensee MDPI, Basel, Switzerland. This article is an open access article distributed under the terms and conditions of the Creative Commons Attribution (CC BY) license (https:// creativecommons.org/licenses/by/ $4.0 /)$.

\begin{abstract}
The mitogen-activated protein kinase (MAPK) cascades have been validated playing critical roles in diverse aspects of plant biology, from growth and developmental regulation, biotic and abiotic stress responses, to phytohormone signal transduction or responses. A classical MAPK cascade consists of a MAPK kinase kinase (MAPKKK), a MAPK kinase (MAPKK), and a MAPK. From the 75 MAPKKKs, eight MAPKKs, and 15 MAPKs of rice, a number of them have been functionally deciphered. Here, we update recent advances in knowledge of the roles of rice MAPK cascades, including their components and complicated action modes, their diversified functions controlling rice growth and developmental responses, coordinating resistance to biotic and abiotic stress, and conducting phytohormone signal transduction. Moreover, we summarize several complete MAPK cascades that harbor OsMAPKKK-OsMAPKK-OsMAPK, their interaction with different upstream components and their phosphorylation of diverse downstream substrates to fulfill their multiple roles. Furthermore, we state a comparison of networks of rice MAPK cascades from signal transduction crosstalk to the precise selection of downstream substrates. Additionally, we discuss putative concerns for elucidating the underlying molecular mechanisms and molecular functions of rice MAPK cascades in the future.
\end{abstract}

Keywords: MAPK cascade; phosphorylation; rice; growth and development; biotic and abiotic stress; phytohormone signal transduction

\section{Introduction}

The mitogen-activated protein kinase (MAPK) cascades have been designated to be highly conserved signal transduction modules in eukaryotes with diverse functions by linking different extracellular stimuli to a wide range of intracellular responses [1,2]. A complete MAPK cascade mainly consists of three kinases, including a MAPK kinase kinase (MAPKKK or MEKK), a MAPK kinase (MAPKK or MEK), and a MAPK (MPK). Upon sensing external stimulus signal, MAPKKKs phosphorylate and activate MAPKKs, the activated MAPKKs subsequently phosphorylate MAPKs, and finally the activated MAPKs phosphorylate a large number of specific downstream substrates, such as transcription factors, chromatin remodeling factors, kinases or other enzymes, leading to reprogramming of transcriptome and proteome in the whole cell. The sequential phosphorylation is fundamental for MAPK cascade-mediated signal transduction and interactions between MAPK proteins and their substrates [3].

In plants, the MAPK cascades play essential roles in growth and developmental regulation, biotic and abiotic stress responses, phytohormone signal transduction or responses [1,4-7]. After receiving external signals, plant MAPKKKs mostly phosphorylate the two conserved serine $(S)$ and threonine $(\mathrm{T})$ residues in the S/T-X5-S/T (X is any amino acid) motif of MAPKKs and activate MAPKKs. The activated MAPKKs in turn phosphorylate both the threonine (T) and the tyrosine (Y) in the T-D-Y or T-E-Y motif of MAPKs and activate MAPKs. However, plant MAPK cascade-mediated signal transduction needs to be precisely regulated, as continuous activation or suppression of MAPK signaling cause 
side-effects for the normal growth of plants. Thus, plant MAPKs can reversely phosphorylate MAPKKKs to regulate the MAPK cascade, precisely controlling signal transduction or responses [8].

\section{Component of Rice MAPK Cascades}

The rice genome contains 75 OsMAPKKKs, 8 OsMAPKKs and 15 OsMAPKs $[9,10]$. The OsMAPKKKs, occupying the largest group of rice MAPK cascade proteins, are divided into three families, including 43 Raf family OsMAPKKKs, 22 MEKK family OsMAPKKKs, and 10 ZIK family OsMAPKKKs [10]. Although the rice genome harbors eight OsMAPKKs, two of them could not be detected on transcriptional levels in different rice tissues, and are considered as pseudogenes, thus there are only six functional MAPKKs in rice [11]. The MAPKs are divided into two subtypes, T-E-Y and T-D-Y, according to the conserved T-X-Y motif in their active loop that specifically phosphorylated by MAPKKs. Of these, T-E-Y subtype contains five OsMAPKs, T-D-Y subtype has 10 OsMAPKs [11].

So far, nine of 75 OsMAPKKKs (OsMAPKKK1, OsMAPKKK6, OsMAPKKK10, OsMAPKKK11, OsMAPKKK18, OsMAPKKK24, OsMAPKKK43, OsMAPKKK62, OsMAPKKK63), five of eight OsMAPKKs (OsMAPKK1, OsMAPKK3, OsMAPKK4, OsMAPKK6, OsMAPKK10-2), and ten of 15 OsMAPKs (OsMAPK3, OsMAPK4, OsMAPK6, OsMAPK7, OsMAPK14, OsMAPK16, OsMAPK17-1, OsMAPK17-2, OsMAPK20-4, OsMAPK20-5) have been functionally characterized (Table 1). OsMAPKKKs, OsMAPKKs and OsMAPKs play roles in rice growth and development, such as plant architecture, leaf morphology, embryogenesis, seed development, seed dormancy, panicle size, and grain size. They also have crucial roles in response to biotic stress, positively or negatively regulating rice resistance to pathogens including Magnaporthe oryzae (M. oryzae), Xanthomonas oryzae pv. oryzae (Xoo), Xanthomonas oryzae pv. oryzicola (Xoc), Burkholderia glumae (B. glumae) and Rhizoctonia solani (R. solani), and to herbivores including striped stem borer (SSB) and brown planthopper (BPH). Similarly, these MAPKs function in response to abiotic stress, such as drought, cold, salt or submergence stress. Alternatively, a number of MAPKs participate in phytohormone accumulation, signal transduction or response, such as abscisic acid (ABA), salicylic acid (SA), jasmonic acid (JA), ethylene (ET), brassinosteroids (BR) or cytokinin (CK).

Table 1. Function characterized rice MAPK genes.

\begin{tabular}{|c|c|c|c|c|}
\hline Gene Name ${ }^{a}$ & Gene Locus ${ }^{b}$ & Alternative Names & Biological Functions ${ }^{c}$ & References \\
\hline OsMAPKKK1 & Os03g06410 & $\begin{array}{l}\text { SPL3/OsEDR1/ } \\
\text { OsACDR1 }\end{array}$ & $\begin{array}{c}\text { M. oryzae }{ }^{+}, \mathrm{Xoo}^{-}, \mathrm{SA}^{-} / \mathrm{JA}^{-} / \mathrm{ET}^{+} \text {accumulation, } \\
\mathrm{ABA}^{+} \text {response }\end{array}$ & [12-15] \\
\hline OsMAPKKК 6 & Os02g50970 & OsDSM1 & Drought stress $^{+}$ & [16] \\
\hline OsMAPKKK10 & Os04g47240 & SMG2 & $\begin{array}{l}\text { Panicle and grain size }{ }^{+} \text {, architecture }{ }^{+}, \mathrm{BR}^{+} \\
\text {response, } \mathrm{CK}^{-} \text {accumulation }\end{array}$ & [17-19] \\
\hline OsMAPKKK11 & Os07g02780 & & Chitin response $^{+}$ & [20] \\
\hline OsMAPKKK18 & Os03g55560 & & Chitin response $^{+}$ & [20] \\
\hline OsMAPKKK24 & Os04g56530 & OsMAPKKKE & M. oryzae ${ }^{+}$ & [21] \\
\hline OsMAPKKK43 & Os06g50920 & OsILA1 & Leaf morphology ${ }^{-}$ & {$[22,23]$} \\
\hline OsMAPKKK62 & Os01g50420 & & $\begin{array}{l}\text { Seed dormancy } \\
\text { ABA }^{-} \text {response }\end{array}$ & [24] \\
\hline OsMAPKKK63 & Os01g50370 & & Salt stress ${ }^{-}$, seed dormancy ${ }^{-}, \mathrm{ABA}^{-}$response & [25] \\
\hline OsMAPKK1 & Os06g05520 & OsMEK2 & Salt stress $^{+}$ & {$[26]$} \\
\hline OsMAPKK10-2 & Os03g12390 & OsMEK3 & $\begin{array}{c}\text { M. oryzae }{ }^{+}, \mathrm{Xoc}^{+}, \\
\text {drought stress }{ }^{+}, \mathrm{SA}^{+} / \mathrm{ABA}^{+} \text {response }\end{array}$ & [27-29] \\
\hline OsMAPKK3 & Os06g27890 & OsMEK8a & $\mathrm{Xoo}^{+}, \mathrm{BPH}^{+}$, seed dormancy ${ }^{-}, \mathrm{ABA}^{-}$response & {$[24,30,31]$} \\
\hline OsMAPKK4 & Os02g54600 & SMG1/OsMEK6 & $\begin{array}{l}\text { M. oryzae } e^{+} \text {, panicle and grain size }{ }^{+}, \text {architecture }^{+}, \\
\mathrm{BR}^{+} \text {response, } \mathrm{CK}^{-} \text {accumulation }\end{array}$ & {$[32,33]$} \\
\hline
\end{tabular}


Table 1. Cont.

\begin{tabular}{|c|c|c|c|c|}
\hline Gene Name $^{a}$ & Gene Locus ${ }^{b}$ & Alternative Names & Biological Functions $^{c}$ & References \\
\hline OsMAPKK6 & Os01g32660 & OsMEK1 & Cold and salt stress ${ }^{+}$ & {$[34,35]$} \\
\hline OsMAPK3 & Os03g17700 & $\begin{array}{l}\text { OsBIMK1/OsMAP1/ } \\
\text { OsMSRMK2/OsMPK5/ } \\
\text { OsMAPK2/OsMPK3 }\end{array}$ & $\begin{array}{l}\text { M. oryzae }{ }^{-}, \mathrm{Xoo}^{-}, \mathrm{SSB}^{+}, \\
\text {B. glumae }{ }^{-}, \text {cold and drought stress } \\
\mathrm{ABA}^{+} / \mathrm{JA}^{+} \text {response }\end{array}$ & [36-39] \\
\hline OsMAPK4 & Os10g38950 & OsMPK6 & $\begin{array}{c}\mathrm{Xoo}^{+-}, \mathrm{SSB}^{+}, \text {salt stress }{ }^{+}, \text {seed development } \\
\mathrm{SA}^{+} / \mathrm{JA}^{+} \text {accumulation }\end{array}$ & [40-43] \\
\hline OsMAPK6 & Os06g06090 & $\begin{array}{l}\text { OsMPK1/ } \\
\text { OsSIPK/DSG1/ } \\
\text { OsMPK6 }\end{array}$ & $\begin{array}{l}\text { M. oryzae }{ }^{+}, \mathrm{Xoc}^{+}, \text {embryogenesis, panicle and } \\
\text { grain size }{ }^{+}, \mathrm{SA}^{+} / \mathrm{BR}^{+} \text {response, } \mathrm{ABA}^{-} / \mathrm{CK}^{-} \\
\text {accumulation }\end{array}$ & {$[28,33,44,45]$} \\
\hline OsMAPK7 & Os06g48590 & $\begin{array}{l}\text { OsMPK4/OsAMPK4/ } \\
\text { OsMPK7/OsMSRMK3 }\end{array}$ & $\mathrm{Xoo}^{+}$, seed dormancy ${ }^{-}, \mathrm{ABA}^{-}$response & {$[24,30,46]$} \\
\hline OsMAPK14 & Os02g05480 & $\begin{array}{c}\text { OsMAPK33/OsMPK3/ } \\
\text { OsMAPK3 }\end{array}$ & Seed dormancy ${ }^{-}, \mathrm{ABA}^{-}$response & {$[24,47]$} \\
\hline OsMAPK16 & Os11g17080 & OsMPK15 & M. oryzae ${ }^{-}, \mathrm{Xoo}^{-}, \mathrm{SA}^{-} / \mathrm{JA}^{-}$accumulation & [48] \\
\hline $\begin{array}{l}\text { OsMAPK17-1 } \\
\text { OsMAPK17-2 }\end{array}$ & $\begin{array}{l}\text { Os06g49430 } \\
\text { Os02g04230 }\end{array}$ & $\begin{array}{l}\text { OsMPK12/ } \\
\text { OsBWMK1 } \\
\text { OsBIMK2/ } \\
\text { OsMPK13 }\end{array}$ & $\begin{array}{c}\mathrm{Xoo}^{+}, \mathrm{SA}^{+} \text {accumulation } \\
\text { Transcriptionally induced by SA }\end{array}$ & $\begin{array}{c}{[37,49]} \\
{[50]}\end{array}$ \\
\hline $\begin{array}{l}\text { OsMAPK20-4 } \\
\text { OsMAPK20-5 }\end{array}$ & $\begin{array}{l}\text { Os01g } 47530 \\
\text { Os05g } 49140\end{array}$ & $\begin{array}{l}\text { OsMPK8/ } \\
\text { OsMPKG1 } \\
\text { OsMPK7 }\end{array}$ & $\begin{array}{c}\text { Transcriptionally induced by ABA } \\
\text { M. oryzae }{ }^{+}, \text {R. solani }{ }^{-}, \mathrm{BPH}^{-}, \mathrm{ET}^{-} \text {accumulation }\end{array}$ & $\begin{array}{c}{[51]} \\
{[52,53]}\end{array}$ \\
\hline
\end{tabular}

${ }^{\mathrm{a}}$ The names of rice MAPKs are used according to reference $[9,11,54] .{ }^{\mathrm{b}}$ Locus ID from Rice Genome Annotation Release $7 .{ }^{\mathrm{c}} M$. oryzae: Magnaporthe oryzae; Xoo: Xanthomonas oryzae pv. oryzae; Xoc: Xanthomonas oryzae pv. oryzicola; B. glumae: Burkholderia glumae; R. solani: Rhizoctonia solani; SSB: striped stem borer; BPH: brown planthopper; ABA: abscisic acid; SA: salicylic acid; JA: jasmonic acid; ET: ethylene; BR: brassinosteroids; CK: cytokinin. ${ }^{+}$Playing positive role. ${ }^{-}$Playing negative role.

A host of plant MEKK family MAPKKKs are considered bona fide MAPKKKs, which can directly phosphorylate the activation loop of downstream MAPKKs, and act the same pattern similar to MAPKKKs of animals and yeast. In contrast, several plant Raf family MAPKKKs can interact with downstream MAPKKs to promote MAPKKs degradation or suppress phosphorylation activity of MAPKKs on its direct downstream substrate MAPKs, but not directly phosphorylate and activate MAPKKs. Thus, some references suggest to exclude these plant Raf family MAPKKKs from bona fide MAPKKKs [54-58]. Compared with OsMAPKKs and OsMAPKs, rice has a great number of OsMAPKKKs, and more than half are Raf family MAPKKKs, the non-canonical MAPKKKs. Among the nine functionally characterized OsMAPKKKs, six of them (OsMAPKKK10, OsMAPKKK11, OsMAPKKK18, OsMAPKKK24, OsMAPKKK62, OsMAPKKK63) belong to MEKK family MAPKKKs, of which OsMAPKKK10, OsMAPKKK11, OsMAPKKK18, and OsMAPKKK24 have been validated as bona fide MAPKKKs with the capacity that to directly phosphorylate and activate downstream MAPKKs [17-21]. Three functionally characterized OsMAPKKKs (OsMAPKKK1, OsMAPKKK6, OsMAPKKK43) are members of Raf family. Whether they can associate with or phosphorylate the downstream OsMAPKKs to activate or suppress the OsMAPKKs is unclear so far [12-16,22,23]. Of the ten functionally studied OsMAPKs, OsMAPK3, OsMAPK4 and OsMAPK6 are T-E-Y subtype MAPKs, the other seven (OsMAPK7, OsMAPK14, OsMAPK16, OsMAPK17-1, OsMAPK17-2, OsMAPK20-4, OsMAPK20-5) are T-D-Y subtype MAPKs. Only a few of them are validated as substrates and can be phosphorylated by upstream OsMAPKKs, such as OsMAPK3, OsMAPK6, OsMAPK7, and OsMAPK14 [24,28,30,33].

A complete MAPK cascade consists of MAPKKK, MAPKK and MAPK [3]. Several integrative rice MAPK cascades have recently been identified involved in diverse physiological processes. OsMAPKKK11/18/24-OsMAPKK4/5-OsMAPK3/ 6 cascades func- 
tion downstream of OsCERK1-OsRLCK185 complex and confer rice resistance to fungal pathogen $M$. oryzae $[20,21]$. OsMAPKKK10-OsMAPKK4-OsMAPK6 cascade plays critical roles in rice grain morphogenesis, rice panicle development, $\mathrm{BR}$ homeostasis and signaling pathway [17-19]. OsMAPKKK62-OsMAPKK3-OsMAPK7/14 cascades affect ABA signal transduction, ABA content and seed dormancy [24]. OsMAPKKK63-OsMAPKK1OsMAPK4 cascade regulates salt stress response $[25,26]$. Apart from these complete MAPK cascades, the other cascades consisting of either OsMAPKKK-OsMAPKK or OsMAPKKOsMAPK lack downstream substrate OsMAPKs or upstream OsMAPKKKs, respectively. OsMAPKKK63-OsMAPKK6 cascade regulates seed dormancy, while the downstream substrate OsMAPKs have not been identified [25]. Additionally, OsMAPKK3-OsMAPK7 cascade is involved in rice resistance to bacterial pathogen Xoo [30], and OsMAPKK6OsMAPK3 cascade participates in cold stress response [34,35], but their corresponding upstream OsMAPKKKs are unclear.

\section{Complicated Action Mode of Rice MAPK Cascades}

Compared with 75 OsMAPKKKs and 15 OsMAPKs, rice contains six functional OsMAPKKs, implying that an OsMAPKK can be phosphorylated by multiple upstream OsMAPKKKs, and similarly a OsMAPKK can phosphorylate and activate several downstream OsMAPKs as its substrate. It seems that OsMAPKKs function as key nodes or hubs in MAPK cascades [59]. Of the five functionally deciphered OsMAPKKs, OsMAPKK4 typically acts as a hub of MAPK cascades, since OsMAPKKK10, OsMAPKKK11, OsMAPKKK18, and OsMAPKKK24 can separately phosphorylate OsMAPKK4 [20,21]. OsMAPKK4, in turn, can simultaneously phosphorylate and activate both OsMAPK3 and OsMAPK6 [33]. When phosphorylated by different OsMAPKKKs after rice sensing different external signals, OsMAPKK4 can select different downstream OsMAPKs for subsequential signal transduction. After rice sensing chitin-triggered signal or recognizing fungal pathogen M. oryzae invasion, OsMAPKK4 is rapidly phosphorylated by OsMAPKKK11, OsMAPKKK18 or OsMAPKKK24, then OsMAPKK4 subsequently phosphorylates OsMAPK3 and OsMAPK6 to transfer signals to downstream transcription factors, promoting rice resistance to $M$. oryzae $[20,21]$. However, when rice senses a BR signal, OsMAPKK4 is phosphorylated by OsMAPKKK10, then OsMAPKK4 phosphorylates OsMAPK6 for downstream signal transduction [17-19].

As mentioned above that different MAPKKKs can phosphorylate a MAPKK, whereas, different MAPKKs can also phosphorylate a MAPK. For example, OsMAPKK1, OsMAPKK3, OsMAPKK4, OsMAPKK5, and OsMAPKK10-2 can interact with and phosphorylate OsMAPK6, mediating rice resistance to fungal and bacterial pathogens or regulating rice growth and developmental responses $[17,18,27,28,33]$. OsMAPKK4, OsMAPKK6, and OsMAPKK10-2 can associate with and phosphorylate OsMAPK3, being involved in defense response, cold tolerance, and drought tolerance, respectively $[28,29,33,34,54,60]$.

In turn, a MAPKK can phosphorylate and activate several MAPKs, including OsMAPKK1 can target OsMAPK4 and OsMAPK6 [26,54,60], OsMAPKK10-2 phosphorylates OsMAPK3 and OsMAPK6 [27-29], OsMAPKK3 interacts with OsMAPK6, OsMAPK7 and OsMAPK14 $[24,30,54,60]$, OsMAPKK6 associates with OsMAPK3, OsMAPK4 and OsMAPK6 $[29,54,60,61]$. The present data uncover that a MAPKK can interact with several MAPKs to play roles in different physiological processes. OsMAPKK10-2 regulates rice resistance to fungal pathogen M. oryzae and bacterial pathogen Xoc by activating OsMAPK6, while modulates drought tolerance via activation of OsMAPK3 $[27,28]$. It indicates that there are complex action modes of rice MAPK cascades, which largely determine their multiple roles.

\section{Controlling Growth and Development by Rice MAPK Cascades}

Like MAPK cascade regulates cell proliferation and cell differentiation to influence plant growth or development, some members of rice MAPK cascades control embryogene- 
sis, fertility, seed development, grain performance, panicle morphogenesis, and architecture (Table 1).

MAPK cascades play critical roles in rice embryogenesis. Functional analysis of lossof-function mutants of OsMAPK6 reveals that OsMAPK6 affects the differentiation of L1 layer cells during early embryogenesis to arrest the embryonic development at the globular stage via influencing GA and auxin synthesis [45]. By screening of a series of osmapk mutants generated via CRISPR-Cas9 technology, heterozygous osmapk6 mutants can produce homozygous osmapk6 seeds but with abnormal embryo [42], while heterozygous osmapk4 mutants do not produce homozygous osmapk4 seeds, implying OsMAPK6 and OsMAPK4 influence seed development [42].

MAPK cascades play key roles in rice grain size and panicle morphogenesis. By screening mutants with altered grain size, smg1 mutant with multiple phenotypes, including small grains, erect leaves, dense and erect panicles has been identified. Genetic analysis indicates that smg1 is loss-of-function of OsMAPKK4, which influences cell proliferation and BR signal [32]. Meanwhile, a natural mutant, $d s g 1$ with pleiotropic phenotypes, including significant dwarfism, small grains, erect and dark-green leaves has been identified. Complement genetic assay indicates that pleiotropic phenotypes of $d s g 1$ are caused by loss of OsMAPK6. Subsequently, genetic analysis indicates that OsMAPKK4 acts upstream of OsMAPK6, by phosphorylating and activating OsMAPK6 to influence cell proliferation [62]. Recently, OsMAPKKK10 has been validated to regulate rice grain size and panicle development via activating OsMAPKK4-OsMAPK6 cascade by a series of genetic and biochemical analysis $[17,18]$. The OsMAPKKK10-OsMAPKK4-OsMAPK6 is so far the only completely known MAPK cascade, which regulates rice growth and development. The latest data have uncovered that plasma membrane localized receptor kinase OsER1 acts directly upstream of OsMAPKKK10-OsMAPKK4-OsMAPK6 cascade. The phosphorylated OsMAPK6 can subsequently phosphorylate OsDST1, then the phosphorylated OsDST1 binds to the promoter of OsCKX2 and promotes the transcription of OsCKX2 [17-19]. The whole signal transduction pathway, from plasma membrane OsER1 to cytoplasm OsMAPKKK10-OsMAPKK4-OsMAPK6, then to nucleus OsCKX2, uncovers a practically perfect genetic regulating network which regulates rice panicle morphogenesis, except the only gap between OsER1 and OsMAPKKK10 (Figure 1).

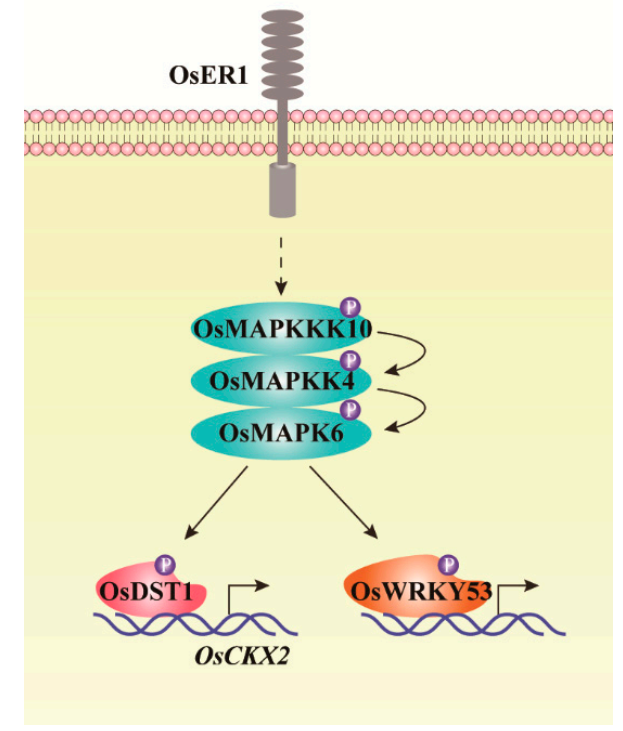

Figure 1. Schematic diagram of MAPK cascade regulating rice panicle and grain development. Plasma membrane localized receptor kinase OsER1 acts directly upstream of OsMAPKKK10OsMAPKK4-OsMAPK6 cascade. The phosphorylated OsMAPK6 can phosphorylate OsDST1, then the phosphorylated OsDST1 targets and promotes the transcription of OsCKX2, regulating rice panicle morphology. Simultaneously, OsMAPKKK10-OsMAPKK4-OsMAPK6 cascade can phosphorylate OsWRKY53 to regulate rice BR signal transduction to alter rice architecture [17-19,63]. 
MAPK cascades function in rice architecture formation via modulating leaf morphology and plant height. The osmapkkk43 mutant caused by a T-DNA insertion shows an increased leaf angle. Following cell biology and genetic assays indicate that OsMAPKKK43 regulates mechanical tissue formation to modify leaf lamina joint by modulating secondary wall synthesis [22,23].

\section{Coordinating Biotic Stress Response by Rice MAPK Cascades}

A great number of plant MAPK cascades, especially of Arabidopsis MAPK cascades, have positive or negative effects on pathogens or insects invasion. Several rice MAPK cascades have been validated to coordinate biotic response and trigger resistance to bacterial and fungal pathogens or herbivores (Table 1).

MAPK cascades confer resistance to fungal pathogens. At least two OsMAPKKKs, two OsMAPKKs, and four OsMAPKs have been reported to be involved in resistance to fungal pathogen M. oryzae. Both OsMAPKKK1 and OsMAPKKK24 play positive roles in resistance to $M$. oryzae, while employing different molecular mechanisms. OsMAPKKK1 triggers resistance to $M$. oryzae by modulating ET biosynthesis to inhibit fungi penetration into rice cells, and OsMAPKKK24 by activating OsMAPKK4-OsMAPK6 cascade $[12,13,21]$. Both OsMAPKKK11 and OsMAPKKK18 are activated by chitin, the fungal microbial-associated molecular pattern. However, there is no direct evidence to confirm these two genes enhancing rice resistance to M. oryzae [20]. Of the four OsMAPKs to be involved in resistance to fungal pathogen, OsMAPK3 and OsMAPK16 negatively regulate resistance to $M$. oryzae [36,37,48], while OsMAPK20-5 positively confers resistance to $M$. oryzae [53]. OsMAPK6 is transcriptionally induced by sphingolipid elicitor and chitin, implying that OsMAPK6 possibly plays role in rice-M. oryzae interactions [33,34]. OsMAPKK10-2 can phosphorylate OsMAPK6, causing activated OsMAPK6 to subsequently phosphorylate and enhance the biochemical activity of downstream transcription factor OsWRKY45 to trigger rice resistance to $M$. oryzae [27]. Similarly, OsMAPKK4 phosphorylates and activates OsMAPK3 and OsMAPK6 to confer resistance to M. oryzae, through accumulation of diterpenoid phytoalexin, momilactones and phytocassanes [33]. However, the underlying mechanisms, why phosphorylated OsMAPK 3 and OsMAPK 6 by different upstream OsMAPKKs, cause susceptibility and confer resistance to $M$. oryzae, respectively, are unclear. Apart from being involved in resistance to fungal pathogen M. oryzae, OsMAPK20-5 has been reported simultaneously to be involved in resistance to fungal pathogen $R$. solani [53] By integrating the characterized MAPK cascades, OsMAPKKK11/18/24-OsMAPKK4/5OsMAPK $3 / 6$ cascades are the complete MAPK cascades, which mediate $M$. oryzae-triggered signal transduction and promote rice resistance to $M$. oryzae (Figure 2).

MAPK cascades trigger resistance to bacterial pathogens. Up to now, one OsMAPKKK, two OsMAPKKs, and six OsMAPKs have been referenced to be involved in resistance to bacterial pathogens, Xoo, Xoc or B. glumae. OsMAPKKK1 negatively regulates resistance to Xoo by modulating accumulation of JA and SA [13]. OsMAPKK10-2 functions as a positive regulator in response to Xoc by activating downstream OsMAPK6 [28]. OsMAPKK3 also functions as a positive regulator but in response to Xoo by activating downstream OsMAPK7, with the signal transduction that the activated OsMAPK7 phosphorylates and activates the transcription factor OsWRKY30 to enhance rice resistance to Xoo [30]. Of the six OsMAPKs conferring resistance to bacterial pathogen, OsMAPK3 and OsMAPK16 play negative roles in response to Xoo [37,48], while OsMAPK7 and OsMAPK17-1 play positive roles in resistance to Xoo [30,49]. Interestingly, OsMAPK4 positively confers resistance to Xoo by promoting the accumulation of JA and SA, while it negatively influences resistance to Xoo by negatively regulating systemic acquired resistance, because both OsMAPK4 overexpressing plants and osmapk 4 mutant exhibit enhanced resistance to Xoo [40,41]. In addition, OsMAPK3 is also involved in resistance to B. glumae, a soil bacterium [36]. 


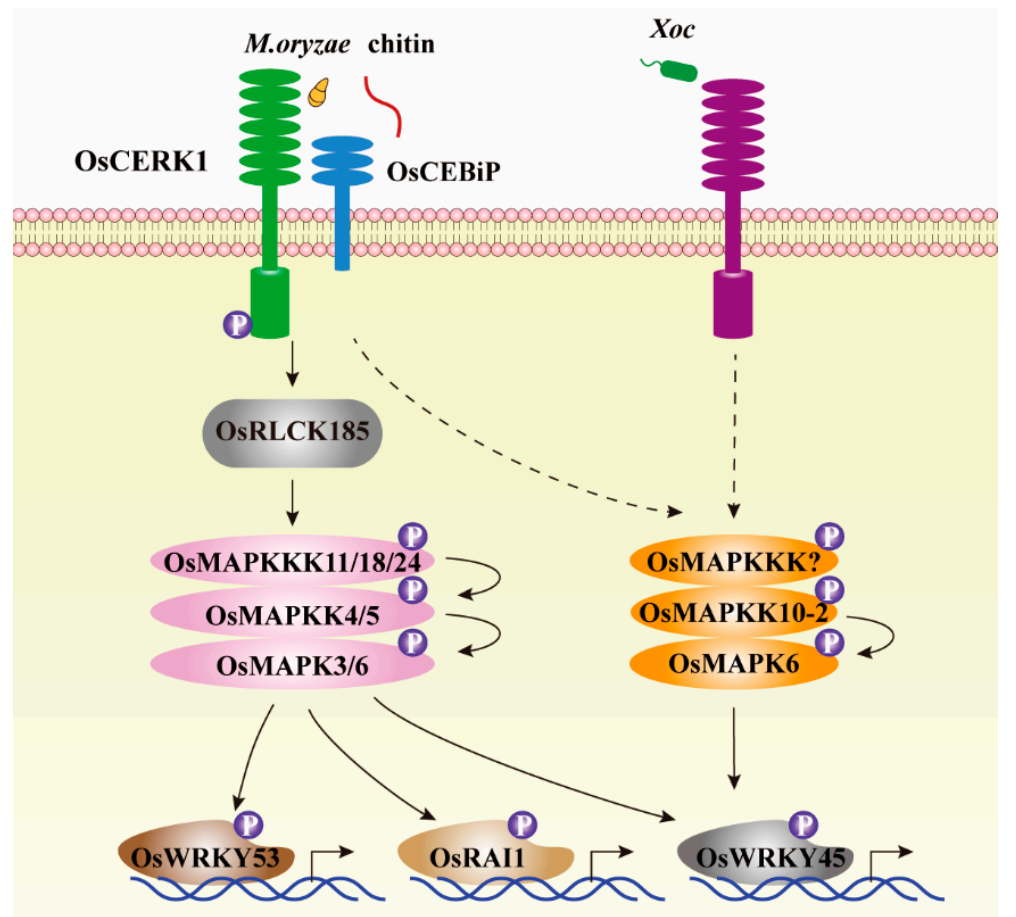

Figure 2. MAPK cascades are downstream of pattern recognition receptors complex and regulate rice immune response. After recognizing chitin or $M$. oryzae, rice pattern recognition receptors complex including OsCERK1 and OsCEBiP that localized at plasma membrane can phosphorylate OsRLCK185 to activate OsMAPKKK11/18/24-OsMAPKK4/5-OsMAPK3/6 cascades, leading to activation of numerous immune-related transcription factors, such as OsWRKY45, OsWRKY53, and OsRAI1 to initiate rice defense response $[20,21,64,65]$. Both fungal pathogen M. oryzae and bacterial pathogen Xoc can activate OsMAPKK10-2-OsMAPK6 cascade via unknown OsMAPKKK to enhance biochemical activity of OsWRKY45, thereby triggering immune response to pathogens [27-29].

MAPK cascades also have roles in resistance to herbivores. Although a number of rice MAPK genes show diverse transcriptional patterns upon herbivores BPH and SSB infection, only one OsMAPKK and three OsMAPKs have been validated exhibiting resistance to $\mathrm{BPH}$ or SSB. OsMAPKK3 functions as a positive regulator in rice-BPH interactions by modulating herbivory-induced phytohormone dynamics [31]. In line with OsMAPKK3, OsMAPK3 and OsMAPK4 also act as positive regulators conferring resistance to SSB with partly similar mechanisms. OsMAPK3 triggers resistance to SSB by regulating JA signaling pathway and promoting accumulation of herbivory-induced trypsin protease inhibitors [39], and OsMAPK4 confers resistance to SSB by regulating JA, ET and SA signaling pathways [43]. Additionally, OsMAPK20-5 which transcriptionally induced by gravid female $\mathrm{BPH}$, negatively regulates rice resistance to $\mathrm{BPH}$ via suppressing the accumulation of ET and NO [52]. It seems that these three OsMAPKs largely regulate resistance to herbivores by modulating phytohormone signaling pathway.

\section{Conferring Resistance to Abiotic Stress by Rice MAPK Cascades}

In addition to biotic stress, rice MAPK cascades have also been confirmed conferring abiotic stress responses, under such as salt, drought, cold, or submergence. For example, OsMAPK3 is the fully characterized MAPK cascade protein which kinase activity is induced by a series of abiotic stress including drought, salt, cold and submergence. The OsMAPK3 overexpressing plants show enhanced resistance to these different abiotic stress [36]. The following research indicates that OsMAPKK6 which acts upstream of OsMAPK3 enhances rice cold tolerance $[34,35]$. The mechanism of OsMAPKK6-OsMAPK3 cascade being involved in cold tolerance is recently been deciphered, with that the activated 
OsMAPK3 interacts with and phosphorylates OsbHLH002/OsICE1, in turn phosphorylated OsbHLH002/OsICE1 binds and promotes the expression of OsTPP1 to cause trehalose accumulation, thereby increasing cold tolerance for rice plants [66]. Whereas, OsMAPK3 has roles in drought tolerance by acting as substrate for OsMAPKKK10-2, the underlying molecular mechanism is unclear [28]. Furthermore, OsMAPK3 has positive effect on salt tolerance by attenuating the reactive oxygen species accumulation [67]. These results demonstrate that OsMAPK3 confers tolerance to salt, drought, or cold stress probably by phosphorylating different substrates (Figure 3).

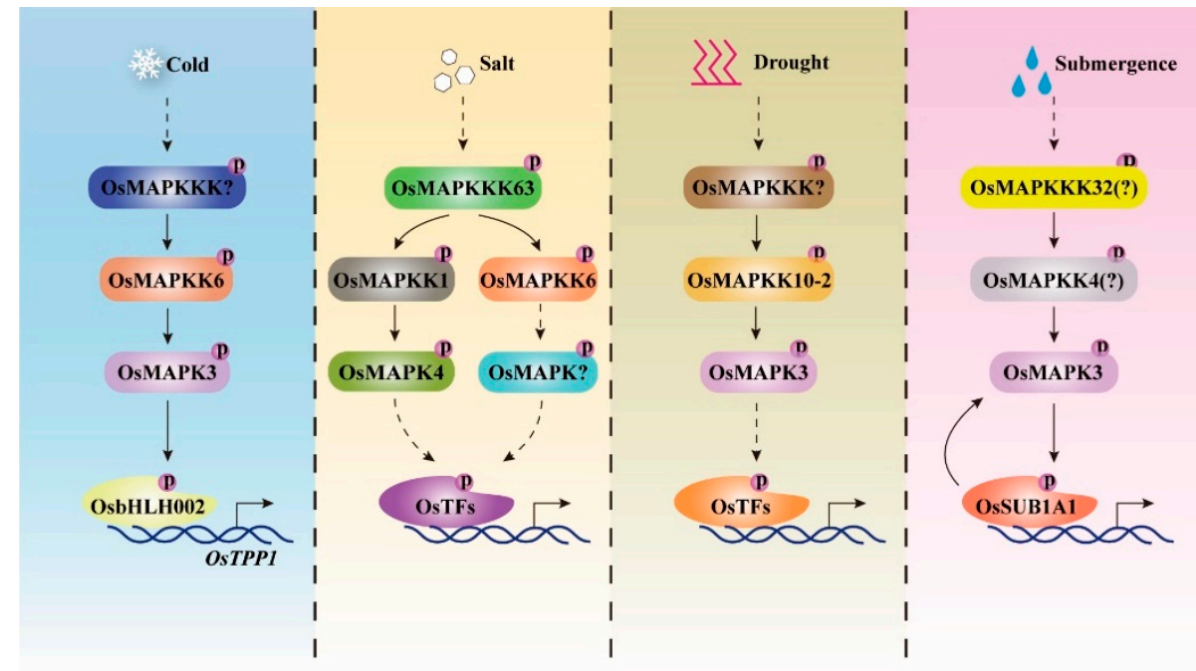

Figure 3. Rice MAPK cascades are activated by different abiotic stress signals and confer tolerance to diverse abiotic stress in rice. A variety of abiotic stress, such as cold, salt, drought, and submergence could activate diverse rice MAPK cascades, which play critical roles in triggering rice resistance to these stresses $[16,25-28,34-36,67,68]$. OsMAPKKK63-OsMAPKK1-OsMAPK4 is the only known cascade conferring salt tolerance, while its downstream substrates have not been identified.

For other MAPKs, OsMAPKK1, its kinase activity is induced by salinity, plays positive roles towards salt stress by phosphorylating and activating downstream substrate OsMAPK4 [26]. Recently, OsMAPKKK63 is found to associate with OsMAPKK1 to enhance rice resistance to salt stress [25]. Thus, a complete MAPK cascade consisting of OsMAPKKK63-OsMAPKK1-OsMAPK4 is identified, which positively promotes rice for salinity tolerance (Figure 3). OsMAPKKK6 functions as a positive regulator towards drought stress by regulating reactive oxygen species scavenging, while its downstream OsMAPKK or OsMAPK are unidentified till now [16].

\section{Conducting Phytohormone Signal Transduction by Rice MAPK Cascades}

As key molecules linking extracellular and intracellular signal transduction, MAPK cascades have been widely reported to participate in phytohormone accumulation, signaling pathways or response, such as ABA, SA, JA, CK, BR or ET. MAPK cascade-mediated phytohormone signal transduction largely contributes to their diverse roles in growth and developmental responses, or biotic and abiotic stress responses. For example, SA treatment can upregulate the transcription of OsMAPKK10-2, the activated OsMAPKK102 phosphorylates and enhances the activity of OsMAPK6, triggering the SA signaling pathway to improve rice resistance to bacterial pathogen Xoc and fungal pathogen $M$. oryzae. Reversely, ABA treatment can induce the transcription of both OsPTP1 and OsPTP2, encoding two tyrosine phosphatases, which two can dephosphorylate the tyrosine residues at the T-E-Y motif of OsMAPK6 and cause the inactivation of OsMAPK6, resulting in decreased resistance to fungal pathogen $M$. oryzae and increased sensitivity to drought stress $[27,28]$. Lately, OsMAPK6 is reported to be a substrate of OsMAPKKK10-OsMAPKK4 cascade being involved in BR signal transduction, modulating rice architecture and grain 
size [17-19]. Furthermore, activated OsMAPK6 by OsMAPKKK10-OsMAPKK4 cascade can also regulate CK metabolism to alter rice panicle development. OsMAPK6 interacts with and phosphorylates OsDST1, then the phosphorylated OsDST1 binds and promotes the transcription of OsCKX2, which encodes the cytokinin oxidase/dehydrogenase. Thereby, activated OsCKX2 accelerates catalyzing the degradation of active CK to alter the number of rice spikelets [19]. Thus, the OsMAPKKK10-OsMAPKK4-OsMAPK6 cascade is closely associated with CK homeostasis in determining rice panicle development (Figure 4). The series of results suggest that different phytohormone signaling pathways can modulate OsMAPK6 function in diverse physiological processes, and OsMAPK6 could also phosphorylate different downstream substrates to regulate phytohormone homeostasis, fine-tuning rice growth and developmental responses as well as biotic and abiotic stress responses.

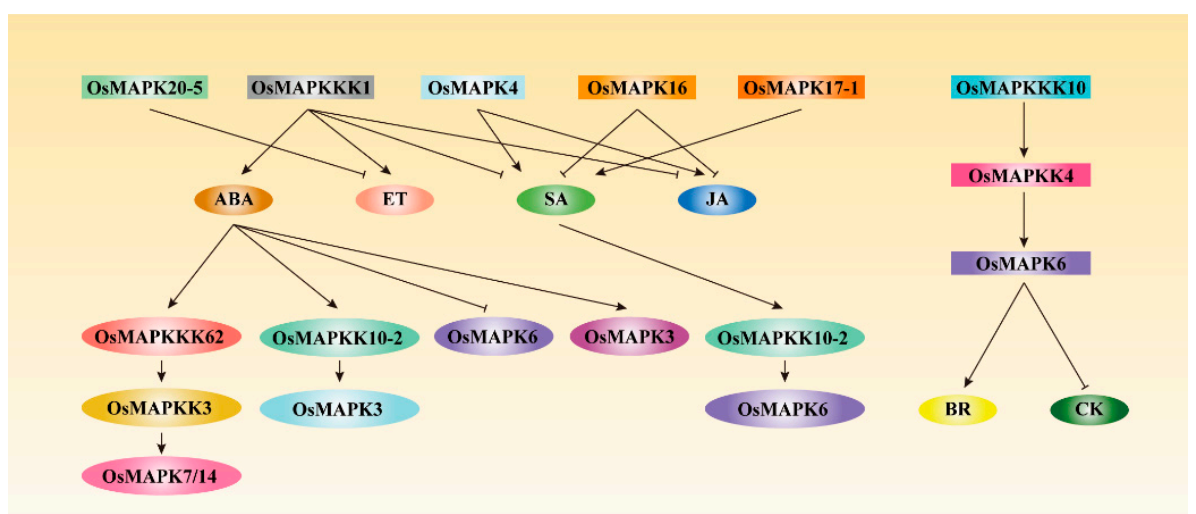

Figure 4. Rice MAPK cascades regulate or are involved in phytohormone accumulation, signal transduction or response. Rice MAPK cascades positively or negatively regulate phytohormone accumulation and signal transduction, or been directly or indirectly modulated by phytohormones, such as SA, JA, ABA, ET, BR, and CK [12-15,27,28,40,43,48,49]. The established OsMAPKKK62OsMAPKK3-OsMAPK7/14 cascades are regulated by ABA, while the OsMAPKKK10-OsMAPKK4OsMAPK6 cascade can regulate BR and CK signal transduction [17-19,24].

In the same way, other MAPK cascades are involved in phytohormone response. For example, the OsMAPKKK62-OsMAPKK3-OsMAPK7/14 and OsMAPKK10-2-OsMAPK3 cascades are associated with ABA signal transduction, regulating rice seed dormancy [24,28]. OsMAPKKK1 acts as a positive regulator in ABA and ET signaling pathways, while as a negative regulator in JA and SA signaling pathways [12-15], implying that OsMAPKKK1 probably interacts with different proteins or phosphorylates different downstream OsMAPKKs to play roles in diverse phytohormone signaling pathways. Similarly, OsMAPK4 positively regulates the accumulation of JA and SA, and OsMAPK17-1 positively regulates the accumulation of SA, while OsMAPK16 negatively regulates the accumulation of JA and SA, and OsMAPK20-5 negatively affects the synthesis of ET $[40,43,48,49]$. These data demonstrate that rice MAPK cascades regulate or involve in complex phytohormone accumulation, signaling pathways or response (Figure 4).

\section{Complex Substrates of Rice MAPK Cascades}

MAPK cascades play roles relying on phosphorylating a variety of downstream substrates, which include transcription factors, chromatin remodeling factors, kinases or other enzymes, and other proteins. So far, nine substrates for OsMAPK3, six substrates for OsMAPK6, one substrate for both OsMAPK4 and OsMAPK7, two substrates for both OsMAPK14 and OsMAPK17-1 have been identified and functionally characterized. Of which majority of substrates are composed of transcription factors (TF), such as WRKY or bHLH, few of them are kinase or other proteins (Table 2). For example, OsMAPK3 phosphorylates OsCDPK18 and OsRAI1 to confer rice resistance to fungal pathogen $M$. oryzae [38,64], acts on OsWRKY30 to confer resistance to bacterial pathogen Xoo [69], 
while phosphorylates OsbHLH002, OsZFP213, SUB1A1 and OsWRKY30 to alter stress tolerance, such as cold, salt, submergence and drought, respectively [66-69]. Occasionally, an OsMAPK could phosphorylate different substrates to regulate the same signaling pathway or play the same roles.

Table 2. Substrates of rice OsMAPKs.

\begin{tabular}{|c|c|c|c|c|c|}
\hline OsMAPK & Substrate & Substrate Protein & Evidence $^{a}$ & Substrate Function & References \\
\hline OsMAPK3 & OsCDPK18 & kinase & 1,2 & M. oryzae ${ }^{-}$ & [38] \\
\hline OsMAPK3 & $\begin{array}{l}\text { OsbHLH002/ } \\
\text { OsICE1 }\end{array}$ & $\mathrm{TF}$ & $1,2,3,4$ & Cold stress $^{+}$ & {$[66]$} \\
\hline OsMAPK3 & OsZFP213 & $\mathrm{TF}$ & 1 & Salt stress ${ }^{+}$ & {$[67]$} \\
\hline OsMAPK3 & OsDRB1 & $\begin{array}{l}\text { double-strand } \\
\text { RNA binding } \\
\text { protein }\end{array}$ & $1,2,3$ & miRNA biogenesis & [70] \\
\hline OsMAPK3 & SUB1A1 & $\mathrm{TF}$ & $1,2,3,4$ & Submergence tolerance ${ }^{+}$ & [68] \\
\hline OsMAPK3 & Bphi008a & Wir1-like protein & 1 & $\mathrm{BPH}^{+}$ & {$[71,72]$} \\
\hline OsMAPK3 & OsRAI1 & $\mathrm{TF}$ & 1,2 & M. oryzae $e^{+}$ & {$[64]$} \\
\hline OsMAPK3 & OsWRKY70 & $\mathrm{TF}$ & 1,2 & $\begin{array}{c}\mathrm{BPH}^{-}, \mathrm{SA}^{-} / \mathrm{GA}^{-} \text {accumulation, } \\
\mathrm{SSB}^{+}, \mathrm{JA}^{+} / \mathrm{ET}^{+} \text {accumulation }\end{array}$ & [73] \\
\hline OsMAPK3 & OsWRKY30 & $\mathrm{TF}$ & $1,2,4$ & Drought stress ${ }^{+}$ & [69] \\
\hline OsMAPK4 & OsWRKY45 & $\mathrm{TF}$ & 2 & $\mathrm{SA}^{+}$signaling & [29] \\
\hline OsMAPK6 & OsWRKY53 & $\mathrm{TF}$ & $1,2,4$ & $\begin{array}{l}\text { M. oryzae }{ }^{+}, \text {grain size }^{+}, \mathrm{BR}^{+} \\
\text {response }\end{array}$ & {$[63,65,74]$} \\
\hline OsMAPK6 & OsDST1 & $\mathrm{TF}$ & 1,2 & $\begin{array}{l}\text { Panicle and grain size }{ }^{-}, \mathrm{CK}^{-} \\
\text {accumulation }\end{array}$ & [19] \\
\hline OsMAPK6 & OsVQ13 & $\begin{array}{c}\text { VQ-motif } \\
\text { containing protein }\end{array}$ & 1 & $\mathrm{Xoo}^{+}, \mathrm{JA}^{+}$response & [75] \\
\hline OsMAPK6 & OsWRKY45 & $\mathrm{TF}$ & 2,4 & M. oryzae ${ }^{+}, \mathrm{SA}^{+}$signaling & {$[27,29]$} \\
\hline OsMAPK6 & OsRAI1 & TF & 1,2 & M. oryzae ${ }^{+}$ & [64] \\
\hline OsMAPK6 & OsWRKY70 & $\mathrm{TF}$ & 1,2 & $\begin{array}{c}\mathrm{SSB}^{+}, \mathrm{JA}^{+} / \mathrm{ET}^{+} \text {accumulation, } \\
\mathrm{BPH}^{-}, \mathrm{SA}^{-} / \mathrm{GA}^{-} \text {accumulation }\end{array}$ & [73] \\
\hline OsMAPK7 & OsWRKY30 & $\mathrm{TF}$ & $1,2,4$ & $\mathrm{XoO}^{+}$, drought stress $^{+}$ & {$[30,69]$} \\
\hline OsMAPK14 & OsWRKY30 & $\mathrm{TF}$ & $1,2,4$ & Drought stress $^{+}$ & [69] \\
\hline OsMAPK14 & OsbHLH65 & $\mathrm{TF}$ & 1,2 & $\begin{array}{l}\text { Transcriptionally induced by } M \text {. } \\
\text { oryzae, BPH, JA/SA treatment }\end{array}$ & [47] \\
\hline $\begin{array}{l}\text { OsMAPK17- } \\
1\end{array}$ & OsWRKY33 & $\mathrm{TF}$ & 1,2 & $\mathrm{SA}^{+}$signaling & [76] \\
\hline $\begin{array}{l}\text { OsMAPK17- } \\
1\end{array}$ & OsEREBP1 & $\mathrm{TF}$ & 1,2 & Defense response $^{+}$ & [77] \\
\hline
\end{tabular}

${ }^{a}$ Evidences provided to validate physiological substrates for the corresponding OsMAPK. 1, in vitro and in vivo interaction analysis. 2, in vitro phosphorylation analysis. 3 , in vivo phosphorylation analysis. 4, mutation of phosphorylated S/T residues-based genetic analysis.

${ }^{+}$Playing positive role. ${ }^{-}$Playing negative role.

OsMAPK3 phosphorylates kinase OsCDPK18 and TF OsRAI1, totally improving rice resistance to $M$. oryzae $[38,64]$. In the same way, OsMAPK6 acts on three different TFs, OsWRKY53, OsWRKY45, and OsRAI1, to collectively trigger rice resistance to $M$. oryzae $[29,64,65]$. Reversely, different OsMAPKs target the same substrate participating in the same physiological processes. For example, both OsMAPK3 and OsMAPK6 phosphorylate OsRAI1 to positively confer rice resistance to fungal pathogen $M$. oryzae [64], and phosphorylate OsWRKY70 to enhance rice resistance to herbivores, BPH and SSB [69,73]. OsMAPK3, OsMAPK7, and OsMAPK14 all can phosphorylate OsWRKY30 to promote rice 
resistance to bacterial pathogen Xoo and modulate rice drought tolerance [69,73]. These data suggest the complex relationships between OsMAPKs and their diverse substrates.

\section{Conclusions}

Tremendous progress has been made to decipher the multiple functions of rice MAPK cascades, with several complete MAPK cascades have been uncovered, including OsMAPKKK11/18/24-OsMAPKK4/5-OsMAPK3/6 cascades, OsMAPKKK10-OsMAPKK4OsMAPK6 cascade, OsMAPKKK63-OsMAPKK1-OsMAPK4 cascade, and OsMAPKKK62OsMAPKK3-OsMAPK7/14 cascades. However, due to over $98 \mathrm{MAPK}$ genes in rice, a large number of them have not been functionally characterized. The gaps need to be filled, including which proteins target OsMAPKKKs, which OsMAPKKs can be phosphorylated by OsMAPKKKs, which OsMAPKs can be phosphorylated by OsMAPKKs, and which proteins can be subsequently phosphorylated by OsMAPKs. Previously, yeast two hybrid and in vitro phosphorylation assay are the main methods for MAPK substrates identification, while these two methods may produce false negatives and positives $[1,60]$. Thus, quantitative phosphoproteomic and immunoprecipitation-mass spectrometry methods have recently been used to identify protein kinase substrates and study the function of protein kinases $[78,79]$. Therefore, the combination of quantitative phosphoproteomic, immunoprecipitation-mass spectrometry, in vitro phosphorylation, and genetic assays would be alternative strategies to uncover the function of MAPKs and identify their substrates. Furthermore, the same MAPK cascade can sense and mediate different signal transduction, playing roles in diverse physiological processes. However, the underlying mechanisms that a MAPK cascade precisely activates and phosphorylates different downstream substrates after sensing different upstream signals are still unclear. Resolving these putative concerns would fully accelerate to elucidate the underlying molecular mechanisms and molecular functions of rice MAPK cascades.

Author Contributions: All the authors J.C., L.W., and M.Y. discussed and created the outline, J.C. and M.Y. wrote the manuscript, and M.Y. revised the manuscript. All authors have read and agreed to the published version of the manuscript.

Funding: This work was supported by grants from the National Natural Science Foundation of China (31821005, 31822042, 31871946), and the Natural Science Foundation of Hubei Province (2020CFA058).

Institutional Review Board Statement: Not applicable.

Informed Consent Statement: Not applicable.

Data Availability Statement: Not applicable.

Conflicts of Interest: The authors declare no conflict of interest.

\section{References}

1. Zhang, M.; Su, J.; Zhang, Y.; Xu, J.; Zhang, S. Conveying endogenous and exogenous signals: MAPK cascades in plant growth and defense. Curr. Opin. Plant Biol. 2018, 45, 1-10. [CrossRef] [PubMed]

2. Komis, G.; Šamajová, O.; Ovečka, M.; Šamaj, J. Cell and developmental biology of plant mitogen-activated protein kinases. Annu. Rev. Plant Biol. 2018, 69, 237-265. [CrossRef]

3. Dóczi, R.; Bögre, L. The quest for MAP kinase substrates: Gaining momentum. Trends Plant Sci. 2018, 23, 918-932. [CrossRef]

4. Pedley, K.F.; Martin, G.B. Role of mitogen-activated protein kinases in plant immunity. Curr. Opin. Plant Biol. $2005,8,541-547$. [CrossRef]

5. Rodriguez, M.C.; Petersen, M.; Mundy, J. Mitogen-activated protein kinase signaling in plants. Annu. Rev. Plant Biol. 2010, 61, 621-649.

6. Xu, J.; Zhang, S. Mitrogen-activated protein kinase cascades in signaling plant growth and development. Trends Plant Sci. 2015, 20, 56-64. [CrossRef] [PubMed]

7. Meng, X.; Zhang, S. MAPK cascades in plant disease resistance signaling. Annu. Rev. Phytopathol. 2013, 51, 245-266. [CrossRef] [PubMed]

8. Bi, G.; Zhou, Z.; Wang, W.; Li, L.; Rao, S.; Wu, Y.; Zhang, X.; Menke, F.L.H.; Chen, S.; Zhou, J.M. Receptor-like cytoplasmic kinases directly link diverse pattern recognition receptors to the activation of mitogen-activated protein kinase cascades in Arabidopsis. Plant Cell 2018, 30, 1543-1561. [CrossRef] 
9. Rao, K.P.; Richa, T.; Kumar, K.; Raghuram, B.; Sinha, A.K. In silico analysis reveals 75 members of mitogen-activated protein kinase kinase kinase gene family in rice. DNA Res. 2010, 17, 139-153. [CrossRef]

10. Yang, Z.; Ma, H.; Hong, H.; Yao, W.; Xie, W.; Xiao, J.; Li, X.; Wang, S. Transcriptome-based analysis of mitogen-activated protein kinase cascades in the rice response to Xanthomonas oryzae infection. Rice 2015, 8, 4. [CrossRef]

11. Hamel, L.P.; Nicole, M.C.; Sritubtim, S.; Morency, M.J.; Ellis, M.; Ehlting, J.; Beaudoin, N.; Barbazuk, B.; Klessig, D.; Lee, J.; et al Ancient signals: Comparative genomics of plant MAPK and MAPKK gene families. Trends Plant Sci. 2006, 11, 192-198. [CrossRef]

12. Kim, J.A.; Cho, K.; Singh, R.; Jung, Y.H.; Jeong, S.H.; Kim, S.H.; Lee, J.E.; Cho, Y.S.; Agrawal, G.K.; Rakwal, R.; et al. Rice OsACDR1 (Oryza sativa accelerated cell death and resistance 1) is a potential positive regulator of fungal disease resistance. Mol. Cells 2009, 28, 431-439. [CrossRef]

13. Shen, X.; Liu, H.; Yuan, B.; Li, X.; Xu, C.; Wang, S. OsEDR1 negatively regulates rice bacterial resistance via activation of ethylene biosynthesis. Plant Cell Environ. 2011, 34, 179-191. [CrossRef] [PubMed]

14. Wang, S.H.; Lim, J.H.; Kim, S.S.; Cho, S.H.; Yoo, S.C.; Koh, H.J.; Sakuraba, Y.; Paek, N.C. Mutation of SPOTTED LEAF3 (SPL3) impairs abscisic acid-responsive signalling and delays leaf senescence in rice. J. Exp. Bot. 2015, 66, 7045-7059. [CrossRef] [PubMed]

15. Kim, J.A.; Agrawal, G.K.; Rakwal, R.; Han, K.S.; Kim, K.N.; Yun, C.H.; Heu, S.; Park, S.Y.; Lee, Y.H.; Jwa, N.S. Molecular cloning and mRNA expression analysis of a novel rice (Oryza sativa L.) MAPK kinase kinase, OsEDR1, an ortholog of Arabidopsis AtEDR1, reveal its role in defense/stress signalling pathways and development. Biochem. Biophys. Res. Commun. 2003, 300, 868-876. [CrossRef]

16. Ning, J.; Li, X.; Hicks, L.M.; Xiong, L. A Raf-like MAPKKK gene DSM1 mediates drought resistance through reactive oxygen species scavenging in rice. Plant Physiol. 2010, 152, 876-890. [CrossRef]

17. Xu, R.; Duan, P.; Yu, H.; Zhou, Z.; Zhang, B.; Wang, R.; Li, J.; Zhang, G.; Zhuang, S.; Lyu, J.; et al. Control of grain size and weight by the OsMKKK10-OsMKK4-OsMAPK6 signaling pathway in rice. Mol. Plant 2018, 11, 860-873. [CrossRef]

18. Guo, T.; Chen, K.; Dong, N.Q.; Shi, C.L.; Ye, W.W.; Gao, J.P.; Shan, J.X.; Lin, H.X. GRAIN SIZE AND NUMBER1 negatively regulates the OsMKKK10-OsMKK4-OsMPK6 cascade to coordinate the trade-off between grain number per panicle and grain size in rice. Plant Cell 2018, 30, 871-888. [CrossRef] [PubMed]

19. Guo, T.; Lu, Z.Q.; Shan, J.X.; Ye, W.W.; Dong, N.Q.; Lin, H.X. ERECTA1 acts upstream of the OsMKKK10-OsMKK4-OsMPK6 cascade to control spikelet number by regulating cytokinin metabolism in rice. Plant Cell 2020, 32, 2763-2779. [CrossRef]

20. Yamada, K.; Yamaguchi, K.; Yoshimura, S.; Terauchi, A.; Kawasaki, T. Conservation of chitin-induced MAPK signaling pathways in rice and Arabidopsis. Plant Cell Physiol. 2017, 58, 993-1002. [CrossRef]

21. Wang, C.; Wang, G.; Zhang, C.; Zhu, P.; Dai, H.; Yu, N.; He, Z.; Xu, L.; Wang, E. OsCERK1-mediated chitin perception and immune signaling requires receptor-like cytoplasmic kinase 185 to activate an MAPK cascade in rice. Mol. Plant 2017, 10, 619-633. [CrossRef] [PubMed]

22. Ning, J.; Zhang, B.; Wang, N.; Zhou, Y.; Xiong, L. Increased leaf angle1, a Raf-like MAPKKK that interacts with a nuclear protein family, regulates mechanical tissue formation in the lamina joint of rice. Plant Cell 2011, 23, 4334-4347. [CrossRef] [PubMed]

23. Zhang, D.; Xu, Z.; Cao, S.; Chen, K.; Li, S.; Liu, X.; Gao, C.; Zhang, B.; Zhou, Y. An uncanonical CCCH-tandem zinc-finger protein represses secondary wall synthesis and controls mechanical strength in rice. Mol. Plant 2018, 11, 163-174. [CrossRef] [PubMed]

24. Mao, X.; Zhang, J.; Liu, W.; Yan, S.; Liu, Q.; Fu, H.; Zhao, J.; Huang, W.; Dong, J.; Zhang, S.; et al. The MKKK62-MKK3-MAPK7/14 module negatively regulates seed dormancy in rice. Rice 2019, 12, 2. [CrossRef]

25. Na, Y.J.; Choi, H.K.; Park, M.Y.; Choi, S.W.; Xuan Vo, K.T.; Jeon, J.S.; Kim, S.Y. OsMAPKKK63 is involved in salt stress response and seed dormancy control. Plant Signal. Behav. 2019, 14, e1578633. [CrossRef] [PubMed]

26. Wang, F.; Jing, W.; Zhang, W. The mitogen-activated protein kinase cascade MKK1-MPK4 mediates salt signaling in rice. Plant Sci. 2014, 227, 181-189. [CrossRef] [PubMed]

27. Ueno, Y.; Yoshida, R.; Kishi-Kaboshi, M.; Matsushita, A.; Jiang, C.J.; Goto, S.; Takahashi, A.; Hirochika, H.; Takatsuji, H. Abiotic stresses antagonize the rice defence pathway through the tyrosine-dephosphorylation of OsMPK6. PLoS Pathog. 2015, 11, e1005231. [CrossRef]

28. Ma, H.; Chen, J.; Zhang, Z.; Ma, L.; Yang, Z.; Zhang, Q.; Li, X.; Xiao, J.; Wang, S. MAPK kinase 10.2 promotes disease resistance and drought tolerance by activating different MAPKs in rice. Plant J. 2017, 92, 557-570. [CrossRef]

29. Ueno, Y.; Yoshida, R.; Kishi-Kaboshi, M.; Matsushita, A.; Jiang, C.J.; Goto, S.; Takahashi, A.; Hirochika, H.; Takatsuji, H. MAP kinases phosphorylate rice WRKY45. Plant Signal. Behav. 2013, 8, e24510. [CrossRef]

30. Jalmi, S.K.; Sinha, A.K. Functional involvement of a mitogen activated protein kinase module, OsMKK3-OsMPK7-OsWRK30 in mediating resistance against Xanthomonas oryzae in rice. Sci. Rep. 2016, 6, 37974. [CrossRef] [PubMed]

31. Zhou, S.; Chen, M.; Zhang, Y.; Gao, Q.; Noman, A.; Wang, Q.; Li, H.; Chen, L.; Zhou, P.; Lu, J.; et al. OsMKK3, a stress-responsive protein kinase, positively regulates rice resistance to Nilaparvata lugens via phytohormone dynamics. Int. J. Mol. Sci. 2019, 20, 3023. [CrossRef]

32. Duan, P.; Rao, Y.; Zeng, D.; Yang, Y.; Xu, R.; Zhang, B.; Dong, G.; Qian, Q.; Li, Y. SMALL GRAIN 1, which encodes a mitogenactivated protein kinase kinase 4 , influences grain size in rice. Plant J. 2014, 77, 547-557. [CrossRef]

33. Kishi-Kaboshi, M.; Okada, K.; Kurimoto, L.; Murakami, S.; Umezawa, T.; Shibuya, N.; Yamane, H.; Miyao, A.; Takatsuji, H.; Takahashi, A.; et al. A rice fungal MAMP-responsive MAPK cascade regulates metabolic flow to antimicrobial metabolite synthesis. Plant J. 2010, 63, 599-612. [CrossRef] [PubMed] 
34. Xie, G.; Kato, H.; Imai, R. Biochemical identification of the OsMKK6-OsMPK3 signalling pathway for chilling stress tolerance in rice. Biochem. J. 2012, 443, 95-102. [CrossRef]

35. Wen, J.Q.; Oono, K.; Imai, R. Two novel mitogen-activated protein signaling components, OsMEK1 and OsMAP1, are involved in a moderate low-temperature signaling pathway in rice. Plant Physiol. 2002, 129, 1880-1891. [CrossRef]

36. Xiong, L.; Yang, Y. Disease resistance and abiotic stress tolerance in rice are inversely modulated by an abscisic acid-inducible mitogen-activated protein kinase. Plant Cell 2003, 15, 745-759. [CrossRef]

37. Seo, Y.S.; Chern, M.; Bartley, L.E.; Han, M.; Jung, K.H.; Lee, I.; Walia, H.; Richter, T.; Xu, X.; Cao, P.; et al. Towards establishment of a rice stress response interactome. PLoS Genet. 2011, 7, e1002020. [CrossRef] [PubMed]

38. Xie, K.; Chen, J.; Wang, Q.; Yang, Y. Direct phosphorylation and activation of a mitogen-activated protein kinase by a calciumdependent protein kinase in rice. Plant Cell 2014, 26, 3077-3089. [CrossRef] [PubMed]

39. Wang, Q.; Li, J.; Hu, L.; Zhang, T.; Zhang, G.; Lou, Y. OsMPK3 positively regulates the JA signaling pathway and plant resistance to a chewing herbivore in rice. Plant Cell Rep. 2013, 32, 1075-1084. [CrossRef]

40. Shen, X.; Yuan, B.; Liu, H.; Li, X.; Xu, C.; Wang, S. Opposite functions of a rice mitogen-activated protein kinase during the process of resistance against Xanthomonas oryzae. Plant J. 2010, 64, 86-99. [CrossRef] [PubMed]

41. Yuan, B.; Shen, X.; Li, X.; Xu, C.; Wang, S. Mitogen-activated protein kinase OsMPK6 negatively regulates rice disease resistance to bacterial pathogens. Planta 2007, 226, 953-960. [CrossRef] [PubMed]

42. Minkenberg, B.; Xie, K.; Yang, Y. Discovery of rice essential genes by characterizing a CRISPR-edited mutation of closely related rice MAP kinase genes. Plant J. 2017, 89, 636-648. [CrossRef] [PubMed]

43. Liu, X.; Li, J.; Xu, L.; Wang, Q.; Lou, Y. Expressing OsMPK4 impairs plant growth but enhances the resistance of rice to the striped stem borer Chilo suppressalis. Int. J. Mol. Sci. 2018, 19, 1182. [CrossRef] [PubMed]

44. Lieberherr, D.; Thao, N.P.; Nakashima, A.; Umemura, K.; Kawasaki, T.; Shimamoto, K. A sphingolipid elicitor-inducible mitogenactivated protein kinase is regulated by the small GTPase OsRac1 and heterotrimeric G-protein in rice. Plant Physiol. 2005, 138, 1644-1652. [CrossRef] [PubMed]

45. Yi, J.; Lee, Y.S.; Lee, D.Y.; Cho, M.H.; Jeon, J.S.; An, G. OsMPK6 plays a critical role in cell differentiation during early embryogenesis in Oryza sativa. J. Exp. Bot. 2016, 67, 2425-2437. [CrossRef]

46. Agrawal, G.K.; Agrawal, S.K.; Shibato, J.; Iwahashi, H.; Rakwal, R. Novel rice MAP kinases OsMSRMK3 and OsWJUMK1 involved in encountering diverse environmental stresses and developmental regulation. Biochem. Biophys. Res. Commun. 2003, 300, 775-783. [CrossRef]

47. Shin, H.Y.; You, M.K.; Jeung, J.U.; Shin, J.S. OsMPK3 is a TEY-type rice MAPK in group C and phosphorylates OsbHLH65, a transcription factor binding to the E-box element. Plant Cell Rep. 2014, 33, 1343-1353. [CrossRef]

48. Hong, Y.; Liu, Q.; Cao, Y.; Zhang, Y.; Chen, D.; Lou, X.; Cheng, S.; Cao, L. The OsMPK15 negatively regulates Magnaporthe oryza and Xoo disease resistance via SA and JA signaling pathway in rice. Front. Plant Sci. 2019, 10, 752. [CrossRef]

49. Xiao, X.; Tang, Z.; Li, X.; Hong, Y.; Li, B.; Xiao, W.; Gao, Z.; Lin, D.; Li, C.; Luo, L.; et al. Overexpressing OsMAPK12-1 inhibits plant growth and enhances resistance to bacterial disease in rice. Funct. Plant Biol. 2017, 44, 694-704. [CrossRef]

50. Song, D.; Chen, J.; Song, F.; Zheng, Z. A novel rice MAPK gene, OsBIMK2, is involved in disease-resistance responses. Plant Biol. 2006, 8, 587-596. [CrossRef]

51. Sheikh, A.H.; Raghuram, B.; Jalmi, S.K.; Wankhede, D.P.; Singh, P.; Sinha, A.K. Interaction between two rice mitogen activated protein kinases and its possible role in plant defense. BMC Plant Biol. 2013, 13, 121. [CrossRef]

52. Li, J.; Liu, X.; Wang, Q.; Huangfu, J.; Schuman, M.C.; Lou, Y. A group D MAPK protects plants from autotoxicity by suppressing herbivore-induced defense signaling. Plant Physiol. 2019, 179, 1386-1401. [CrossRef]

53. Liu, X.; Li, J.; Noman, A.; Lou, Y. Silencing OsMAPK20-5 has different effects on rice pests in the field. Plant Signal. Behav. 2019, 14, e1640562. [CrossRef] [PubMed]

54. Singh, R.; Jwa, N.S. The rice MAPKK-MAPK interactome: The biological significance of MAPK components in hormone signal transduction. Plant Cell Rep. 2013, 32, 923-931. [CrossRef]

55. Zhao, C.; Nie, H.; Shen, Q.; Zhang, S.; Lukowitz, W.; Tang, D. EDR1 physically interacts with MKK4/MKK5 and negatively regulates a MAP kinase cascade to modulate plant innate immunity. PLoS Genet. 2014, 10, e1004389. [CrossRef]

56. Yoo, S.D.; Cho, Y.H.; Tena, G.; Xiong, Y.; Sheen, J. Dual control of nuclear EIN3 by bifurcate MAPK cascades in C2H4 signalling. Nature 2008, 451, 789-795. [CrossRef] [PubMed]

57. Gao, C.; Sun, P.; Wang, W.; Tang, D. Arabidopsis E3 ligase KEG associates with and ubiquitinates MKK4 and MKK5 to regulate plant immunity. J. Integr. Plant Biol. 2020. [CrossRef] [PubMed]

58. Nitta, Y.; Qiu, Y.; Yaghmaiean, H.; Zhang, Q.; Huang, J.; Adams, K.; Zhang, Y. MEKK2 inhibits activation of MAP kinases in Arabidopsis. Plant J. 2020, 103, 705-714. [CrossRef]

59. Dietz, K.J.; Nishiuchi, T.; Nakashita, H.; Nishimura, K.; Sidiq, Y.; Yasuda, M.; Nguyen, T.H.N.; Asano, T. Arabidopsis MAPKKK $\delta-1$ is required for full immunity against bacterial and fungal infection. J. Exp. Bot. 2020, 71, 2085-2097.

60. Singh, R.; Lee, M.O.; Lee, J.E.; Choi, J.; Park, J.H.; Kim, E.H.; Yoo, R.H.; Cho, J.I.; Jeon, J.S.; Rakwal, R.; et al. Rice mitogen-activated protein kinase interactome analysis using the yeast two-hybrid system. Plant Physiol. 2012, 160, 477-487. [CrossRef]

61. Ding, X.; Richter, T.; Chen, M.; Fujii, H.; Seo, Y.S.; Xie, M.; Zheng, X.; Kanrar, S.; Stevenson, R.A.; Dardick, C.; et al. A rice kinase-protein interaction map. Plant Physiol. 2009, 149, 1478-1492. [CrossRef] [PubMed] 
62. Liu, S.; Hua, L.; Dong, S.; Chen, H.; Zhu, X.; Jiang, J.; Zhang, F.; Li, Y.; Fang, X.; Chen, F. OsMAPK6, a mitogen-activated protein kinase, influences rice grain size and biomass production. Plant J. 2015, 84, 672-681. [CrossRef]

63. Tian, X.; Li, X.; Zhou, W.; Ren, Y.; Wang, Z.; Liu, Z.; Tang, J.; Tong, H.; Fang, J.; Bu, Q. Transcription factor OsWRKY53 positively regulates brassinosteroid signaling and plant architecture. Plant Physiol. 2017, 175, 1337-1349. [CrossRef] [PubMed]

64. Kim, S.H.; Oikawa, T.; Kyozuka, J.; Wong, H.L.; Umemura, K.; Kishi-Kaboshi, M.; Takahashi, A.; Kawano, Y.; Kawasaki, T.; Shimamoto, K. The bHLH Rac Immunity1 (RAI1) is activated by OsRac1 via OsMAPK3 and OsMAPK6 in rice immunity. Plant Cell Physiol. 2012, 53, 740-754. [CrossRef] [PubMed]

65. Chujo, T.; Miyamoto, K.; Ogawa, S.; Masuda, Y.; Shimizu, T.; Kishi-Kaboshi, M.; Takahashi, A.; Nishizawa, Y.; Minami, E.; Nojiri, H.; et al. Overexpression of phosphomimic mutated OsWRKY53 leads to enhanced blast resistance in rice. PLoS ONE 2014, 9, e98737. [CrossRef]

66. Zhang, Z.; Li, J.; Li, F.; Liu, H.; Yang, W.; Chong, K.; Xu, Y. OsMAPK3 phosphorylates OsbHLH002/OsICE1 and inhibits its ubiquitination to activate OsTPP1 and enhances rice chilling tolerance. Dev. Cell 2017, 43, 731-743. [CrossRef]

67. Zhang, Z.; Liu, H.; Sun, C.; Ma, Q.; Bu, H.; Chong, K.; Xu, Y. A C2H2 zinc-finger protein OsZFP213 interacts with OsMAPK3 to enhance salt tolerance in rice. J. Plant Physiol. 2018, 229, 100-110. [CrossRef]

68. Singh, P.; Sinha, A.K. A positive feedback loop governed by SUB1A1 interaction with MITOGEN-ACTIVATED PROTEIN KINASE3 imparts submergence tolerance in rice. Plant Cell 2016, 28, 1127-1143. [CrossRef]

69. Shen, H.; Liu, C.; Zhang, Y.; Meng, X.; Zhou, X.; Chu, C.; Wang, X. OsWRKY30 is activated by MAP kinases to confer drought tolerance in rice. Plant Mol. Biol. 2012, 80, 241-253. [CrossRef]

70. Raghuram, B.; Sheikh, A.H.; Rustagi, Y.; Sinha, A.K. MicroRNA biogenesis factor DRB1 is a phosphorylation target of mitogen activated protein kinase MPK3 in both rice and Arabidopsis. FEBS J. 2015, 282, 521-536. [CrossRef]

71. Yuan, H.; Chen, X.; Zhu, L.; He, G. Isolation and characterization of a novel rice gene encoding a putative insect-inducible protein homologous to wheat Wir1. J. Plant Physiol. 2004, 161, 79-85. [CrossRef]

72. Hu, J.; Zhou, J.; Peng, X.; Xu, H.; Liu, C.; Du, B.; Yuan, H.; Zhu, L.; He, G. The Bphi008a gene interacts with the ethylene pathway and transcriptionally regulates MAPK genes in the response of rice to brown planthopper feeding. Plant Physiol. 2011, 156, 856-872. [CrossRef]

73. Li, R.; Zhang, J.; Li, J.; Zhou, G.; Wang, Q.; Bian, W.; Erb, M.; Lou, Y. Prioritizing plant defence over growth through WRKY regulation facilitates infestation by non-target herbivores. Elife 2015, 4, e04805. [CrossRef]

74. Yoo, S.J.; Kim, S.H.; Kim, M.J.; Ryu, C.M.; Kim, Y.C.; Cho, B.H.; Yang, K.Y. Involvement of the OsMKK4-OsMPK1 cascade and its downstream transcription factor OsWRKY53 in the wounding response in rice. Plant Pathol. J. 2014, 30, 168-177. [CrossRef] [PubMed]

75. Uji, Y.; Kashihara, K.; Kiyama, H.; Mochizuki, S.; Akimitsu, K.; Gomi, K. Jasmonic acid-induced VQ-Motif-containing protein OsVQ13 influences the OsWRKY45 signaling pathway and grain size by associating with OsMPK6 in rice. Int. J. Mol. Sci. 2019, 20, 2917. [CrossRef] [PubMed]

76. Koo, S.C.; Moon, B.C.; Kim, J.K.; Kim, C.Y.; Sung, S.J.; Kim, M.C.; Cho, M.J.; Cheong, Y.H. OsBWMK1 mediates SA-dependent defense responses by activating the transcription factor OsWRKY33. Biochem. Biophys. Res. Commun. 2009, 387, 365-370. [CrossRef] [PubMed]

77. Cheong, Y.H.; Moon, B.C.; Kim, J.K.; Kim, C.Y.; Kim, M.C.; Kim, I.H.; Park, C.Y.; Kim, J.C.; Park, B.O.; Koo, S.C.; et al. BWMK1, a rice mitogen-activated protein kinase, locates in the nucleus and mediates pathogenesis-related gene expression by activation of a transcription factor. Plant Physiol. 2003, 132, 1961-1972. [CrossRef]

78. Wang, P.; Hsu, C.C.; Du, Y.; Zhu, P.; Zhao, C.; Fu, X.; Zhang, C.; Paez, J.S.; Macho, A.P.; Tao, W.A.; et al. Mapping proteome-wide targets of protein kinases in plant stress responses. Proc. Natl. Acad. Sci. USA 2020, 117, 3270-3280. [CrossRef]

79. Rayapuram, N.; Bigeard, J.; Alhoraibi, H.; Bonhomme, L.; Hesse, A.M.; Vinh, J.; Hirt, H.; Pflieger, D. Quantitative phosphoproteomic analysis reveals shared and specific targets of Arabidopsis mitogen-activated protein kinases (MAPKs) MPK3, MPK4, and MPK6. Mol. Cell. Proteom. 2018, 17, 61-80. [CrossRef] 